\title{
(6) OPEN ACCESS \\ Certolizumab pegol in combination with dose-optimised methotrexate in DMARD-naïve patients with early, active rheumatoid arthritis with poor prognostic factors: 1-year results from C-EARLY, a randomised, double-blind, placebo-controlled phase III study
}

\author{
P Emery, ${ }^{1,2}$ C O Bingham III, ${ }^{3} \mathrm{G}$ R Burmester, ${ }^{4} \mathrm{~V}$ P Bykerk, $^{5} \mathrm{D}$ E Furst, ${ }^{6} \mathrm{X} \mathrm{Mariette,}^{7}$ \\ $\mathrm{D}$ van der Heijde, ${ }^{8} \mathrm{R}$ van Vollenhoven, ${ }^{9} \mathrm{C} \mathrm{Arendt}_{1}{ }^{10}{ }$ Mountian, $^{10} \mathrm{O}$ Purcaru, $^{10}$ \\ D Tatla, ${ }^{11}$ B VanLunen, M E Weinblatt ${ }^{11,12}$
}

\begin{abstract}
Handling editor Tore K Kvien
- Additional material is published online only. To view please visit the journal online (http://dx.doi.org/10.1136/ annrheumdis-2015-209057)

For numbered affiliations see end of article.

Correspondence to Professor P Emery, Leeds Institute of Rheumatic and Musculoskeletal Medicine, University of Leeds and NIHR Leeds Musculoskeletal Biomedical Research Unit, Leeds Teaching Hospitals NHS Trust, Leeds LS7 4SA, UK; p.emery@leeds.ac.uk
\end{abstract}

Received 18 December 2015 Revised 8 April 2016 Accepted 9 April 2016 Published Online First 10 May 2016

CrossMark

To cite: Emery $\mathrm{P}$, Bingham CO, Burmester GR, et al. Ann Rheum Dis 2017;76:96-104.

\section{ABSTRACT}

Objectives To assess the efficacy and safety of certolizumab pegol (CZP)+dose-optimised methotrexate (MTX) versus placebo (PBO)+dose-optimised MTX in inducing and sustaining clinical remission in DMARDnaive patients with moderate-to-severe, active, progressive rheumatoid arthritis (RA), with poor prognostic factors over 52 weeks.

Methods DMARD-naïve patients with $\leq 1$ year of active RA were randomised $(3: 1)$ in a double-blind manner to CZP (400 mg Weeks 0, 2, 4, then $200 \mathrm{mg}$ Q2W to Week 52)+MTX or PBO+MTX (the mean optimised-MTX dose=21 and $22 \mathrm{mg} /$ week, respectively). Sustained remission (sREM) and sustained low disease activity (sLDA; DAS28(ESR) $<2.6$ and DAS28(ESR) $\leq 3.2$, respectively, at both Weeks 40 and 52) were the primary and secondary endpoints.

Results Patients were randomised to CZP+MTX $(n=660)$ and PBO+MTX ( $n=219)$. At Week 52, significantly more patients assigned to CZP+MTX compared with PBO+MTX achieved sREM $(28.9 \%$ vs $15.0 \%, p<0.001)$ and sLDA (43.8\% vs $28.6 \%$, $\mathrm{p}<0.001)$. Inhibition of radiographic progression and improvements in physical functioning were significantly greater for CZP+MTX versus PBO+MTX (van der Heijde modified total Sharp score (mTSS) mean absolute change from baseline (CFB): 0.2 vs $1.8, p<0.001$, rate of mTSS non-progressors: $70.3 \%$ vs $49.7 \%, p<0.001$; least squares (LS) mean CFB in Health Assessment Questionnaire-Disability Index (HAQ-DI): -1.00 vs $-0.82, p<0.001)$. Incidence of adverse events (AEs) and serious AEs was similar between treatment groups. Infection was the most frequent $A E$, with higher incidence for CZP+MTX (71.8/100 patient-years (PY)) versus PBO+MTX (52.7/100 PY); the rate of serious infection was similar between CZP+MTX (3.3/100 PY) and PBO+MTX (3.7/100 PY).

Conclusions CZP+dose-optimised MTX treatment of DMARD-naïve early RA resulted in significantly more patients achieving SREM and SLDA, improved physical function and inhibited structural damage compared with PBO+dose-optimised MTX.

Trial registration number NCT01519791.

\section{INTRODUCTION}

In patients with rheumatoid arthritis (RA), early treatment helps prevent structural joint damage, resulting in better long-term outcomes. ${ }^{1-3}$ Recent studies suggest that a therapeutic 'window of opportunity' may exist in the early stages of RA when biologics may be more effective, due to the predominance of inflammation over joint damage. ${ }^{4-6}$

Certolizumab pegol (CZP) is a PEGylated, Fc-free anti-TNF. The efficacy of CZP in combination with methotrexate (MTX) has been proven in patients with established RA and insufficient response to MTX alone in the pivotal RAPID1 and RAPID2 studies (the mean disease duration was $\sim 6$ years in both trials). ${ }^{7}{ }^{8}$ More recently, CZP + MTX was shown to be efficacious in MTX-naïve patients with early RA and poor prognostic factors (C-OPERA study, conducted in Japan; the mean disease duration was $\sim 4$ months), ${ }^{9}$ justifying the need for a more thorough examination of the efficacy and safety of CZP+MTX in patients with recently diagnosed RA.

C-EARLY (NCT01519791) is the first randomised double-blind study to assess the efficacy and safety of CZP +MTX versus placebo $(\mathrm{PBO})+\mathrm{MTX}$ treatment over 52 weeks in inducing and sustaining clinical response, and inhibiting radiographic damage, in DMARD-naïve patients with moderate-to-severe, active RA with poor prognostic factors.

\section{METHODS}

\section{Patients}

Eligible patients were DMARD-naïve, diagnosed with $\mathrm{RA} \leq 1$ year prior to randomisation, fulfilled the 2010 American College of Rheumatology (ACR)/European League Against Rheumatism (EULAR) classification criteria ${ }^{10}$ and had poor prognostic factors for severe disease progression (positive for rheumatoid factor (RF) or anticitrullinated peptide antibody (ACPA) at screening). Patients must have had active RA, defined at 
screening and baseline (BL) as $\geq 4$ swollen and $\geq 4$ tender joints (out of 28); DAS28(ESR) $>3.2$ and ESR $\geq 28 \mathrm{~mm} / \mathrm{h}$ and/or C reactive protein (CRP) $\geq 10 \mathrm{mg} / \mathrm{L}$ (CRP at screening only).

Patients were excluded if they had received treatment for RA with any biologic or non-biologic DMARD therapy, including MTX, prior to BL. Non-steroidal anti-inflammatory drugs and oral corticosteroids ( $\leq 10 \mathrm{mg} /$ day prednisone equivalent) were permitted if the BL dose was not exceeded at any point during the study.

Patients with a history of chronic or recurrent infections, serious infections, history of or active tuberculosis (TB), latent TB, malignancy or demyelinating disorders were excluded. Following a protocol amendment, TB testing methods were changed to Interferon Gamma Release Assay (IGRA) testing (QuantiFERON-TB Gold test (ELISpot test if not available)) or a purified protein derivative (PPD) skin test depending on local regulations. Patients were defined as having latent TB if they had a positive IGRA or PPD test ( $\geq 5 \mathrm{~mm}$ of induration) with chest imaging negative for TB infection, or a severe positive PPD reaction and a positive/indeterminate ELISpot or QuantiFERON test $\leq 3$ months prior to screening.

\section{Study design}

C-EARLY was a multicentre, double-blind, PBO-controlled, randomised study conducted in Europe, Australia, North America and Latin America at 181 sites (see online supplementary figure S1). Patients were randomised 3:1 to receive CZP (400 mg subcutaneously at Weeks 0, 2, 4, then $200 \mathrm{mg}$ every 2 weeks to Week 52)+MTX or PBO+MTX. Randomisation at Week 0 was performed centrally using an interactive voice and web response system and was stratified by disease duration of
$>4$ months or $\leq 4$ months. ${ }^{5}$ Following completion of this 52-week study, patients in sustained low disease activity (sLDA; DAS28(ESR) $\leq 3.2$ at both Weeks 40 and 52) were eligible to enter a randomised, double-blind, dose-withdrawal study (C-EARLY Period 2 (NCT01521923); to be completed in 2016). The 3:1 randomisation was used to increase the pool of CZP patients eligible for Period 2 of the study.

Oral MTX was initiated at $10 \mathrm{mg} /$ week and was escalated by $5 \mathrm{mg}$ every 2 weeks, if tolerated, to a maximum of $25 \mathrm{mg} /$ week (minimum $15 \mathrm{mg} /$ week) by Week 8 . The maximum-tolerated dose (optimised MTX) was continued through Week 52.

Patients not achieving sufficient improvement (defined as DAS28(ESR) $\leq 3.2$ and/or $\geq 1.2$-point improvement in DAS28 (ESR) from BL) at Weeks 20 and 24 were withdrawn to allow them to switch to a complementary medication.

All study personnel were blinded to treatment, except for a separate unblinded group who supervised/administered the study medication and determined ESR, but had no other involvement.

\section{Statistical analysis}

Full details of all statistical analyses are described in the online supplementary materials. In brief, the sample size was calculated assuming an expected percentage of patients in sustained remission (sREM) at Week 52 of $50 \%$ in the CZP+MTX group and $30 \%$ in the $\mathrm{PBO}+\mathrm{MTX}$ group. A minimum of $600 \mathrm{CZP}$ patients and $200 \mathrm{PBO}$ patients were required (for 3:1 randomisation). Hypothesis testing was performed on Week 52 data in a hierarchical manner starting with sREM, followed by the secondary endpoints in the following order: sLDA, ACR50, change from baseline (CFB) in the Health Assessment Questionnaire-Disability Index (HAQ-DI) and CFB in the van

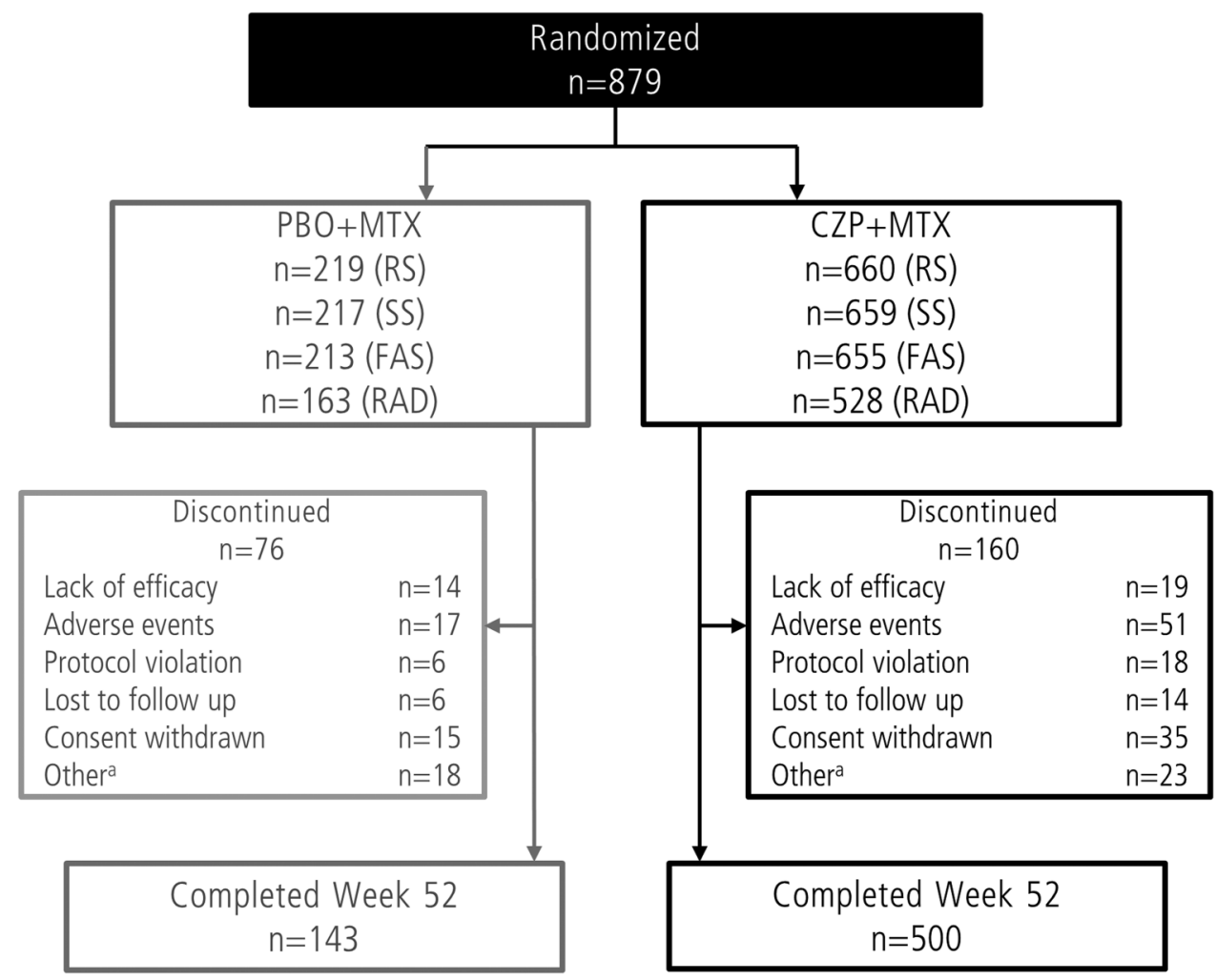

Figure 1 Patient disposition in the C-EARLY study. ${ }^{a}$ Other' included some mandatory withdrawals at Weeks 24 and 36 . In addition, two patients in the certolizumab pegol (CZP)+methotrexate (MTX) group were randomised in error, were not dosed and were withdrawn shortly afterwards as screen failures (these two subjects were included in the RS). Patients completed Week 52 if they had a Week 52 visit. FAS, full analysis set; PBO, placebo; RAD, radiographic set; RS, randomised set; SS, safety set. 


\begin{tabular}{|c|c|c|c|}
\hline Characteristic & $\begin{array}{c}\mathrm{PBO}+\mathrm{MTX} \\
\mathrm{n}=213\end{array}$ & $\begin{array}{c}\mathrm{CZP}+\mathrm{MTX} \\
\mathrm{n}=655\end{array}$ & $\begin{array}{l}\text { All patients } \\
\mathrm{n}=868\end{array}$ \\
\hline Mean age, years (SD) & $51.2(13.0)$ & $50.4(13.6)$ & $50.6(13.5)$ \\
\hline Female, $\mathrm{n}(\%)$ & $170(79.8)$ & $497(75.9)$ & $667(76.8)$ \\
\hline \multicolumn{4}{|l|}{ BMI $\left(\mathrm{kg} / \mathrm{m}^{2}\right)$} \\
\hline $\mathrm{n}$ & 213 & 652 & 865 \\
\hline Mean (SD) & $28.8(6.4)$ & $28.0(6.0)$ & $28.2(6.1)$ \\
\hline \multicolumn{4}{|l|}{ Region, $\mathrm{n}(\%)$} \\
\hline Europe and Australia & $107(50.2)$ & $354(54.0)$ & $461(53.1)$ \\
\hline Latin and North America & $106(49.8)$ & $301(46.0)$ & $407(46.9)$ \\
\hline Systemic corticosteroids, $\mathrm{n}(\%)^{\mathrm{a}}$ & $64(29.5)$ & $222(33.7)$ & $286(32.6)$ \\
\hline DAS28(ESR), mean (SD) & $6.8(0.9)$ & $6.7(0.9)$ & $6.7(0.9)$ \\
\hline Moderate disease activity: $>3.2$ to $\leq 5.1, \mathrm{n}(\%)$ & $10(4.7)$ & $20(3.1)$ & $30(3.5)$ \\
\hline High disease activity: >5.1, n (\%) & $203(95.3)$ & $635(96.9)$ & $838(96.5)$ \\
\hline SDAl, mean (SD) & $44.8(13.9)$ & $43.5(13.6)$ & $43.8(13.7)$ \\
\hline CDAl, mean (SD) & $42.6(12.9)$ & $41.3(12.5)$ & $41.6(12.6)$ \\
\hline HAQ-DI, mean (SD) & $1.7(0.6)$ & $1.6(0.6)$ & $1.6(0.6)$ \\
\hline TJC (28 joints), mean (SD) & $16.2(6.5)$ & $15.6(6.5)$ & $15.8(6.5)$ \\
\hline SJC (28 joints), mean (SD) & $13.0(5.6)$ & $12.4(5.5)$ & $12.5(5.5)$ \\
\hline ESR $(\mathrm{mm} / \mathrm{h})$, median $(\min , \max )$ & $44.0(10.0,135.0)$ & $42.0(2.0,150.0)$ & $43.0(2.0,150.0)$ \\
\hline CRP (mg/L), median (min, max) & $10.5(0.3,243.2)$ & $11.1(0.2,231.1)$ & $11.1(0.2,243.2)$ \\
\hline Months since RA was first diagnosed, mean (SD) & $2.9(2.9)$ & $2.9(4.6)$ & $2.9(4.3)$ \\
\hline$>4$ months, mean (SD) & $7.1(2.5)^{\mathrm{b}}$ & $7.6(7.8)^{c}$ & $7.4(6.8)$ \\
\hline$\leq 4$ months, mean (SD) & $1.4(1.0)^{\mathrm{d}}$ & $1.4(1.0)^{\mathrm{e}}$ & $1.4(1.0)$ \\
\hline Months since first RA symptom, mean (SD) ${ }^{f}$ & $9.6(11.8)^{9}$ & $12.4(32.3)^{\mathrm{h}}$ & $11.7(28.6)$ \\
\hline RF positive ( $\geq 14 \mathrm{IU} / \mathrm{mL}$ ), n (\%) & $206(96.7)$ & $634(96.8)$ & $840(96.8)$ \\
\hline ACPA positive ( $\geq 7 \mathrm{IU} / \mathrm{mL}$ ), $\mathrm{n}(\%)$ & $182(85.4)$ & $546(83.4)$ & $728(83.9)$ \\
\hline mTSS, median (min, max) & $2.8(0,161)$ & $3.0(0,130)$ & $3.0(0,161)$ \\
\hline Mean (SD) & $8.5(17.5)$ & $7.2(13.8)$ & $7.5(14.8)$ \\
\hline$>4$ months, median (min, max) & $5.0(0,106)^{i}$ & $3.0(0,38)^{j}$ & - \\
\hline$\leq 4$ months, median (min, max) & $2.3(0,161)^{\mathrm{k}}$ & $2.5(0,130)^{1}$ & - \\
\hline Erosion score, median (min, max) & $1.5(0,68)$ & $1.5(0,69)$ & $1.5(0,69)$ \\
\hline JSN, median (min, max) & $0(0,94)$ & $0(0,76)$ & $0(0,94)$ \\
\hline Presence of erosions, $\mathrm{n}(\%)$ & $169(79.3)$ & $506(77.3)$ & $675(77.8)$ \\
\hline
\end{tabular}

\footnotetext{
${ }^{a}$ Safety set, all other data are reported for full analysis set; ${ }^{b} n=56 ;{ }^{c} n=153 ;{ }^{d} n=157 ;{ }^{e} n=502 ;{ }^{f}$ data were collected retrospectively; ${ }^{g} n=208 ;{ }^{h} n=631 ;{ }^{i} n=43 ;{ }^{j} n=118 ;{ }^{k} n=120$ and ${ }^{1} n=410$. ACPA, anticitrullinated peptide antibody; CDAl, Clinical Disease Activity Index; CRP, C reactive protein; CZP, certolizumab pegol; HAQ-DI, Health Assessment Questionnaire-Disability Index; JSN, joint space narrowing; mTSS, van der Heijde modified total Sharp score; MTX, methotrexate; PBO, placebo; RA, rheumatoid arthritis; RF, rheumatoid factor; SDAl, Simplified Disease Activity Index.
}

der Heijde modified total Sharp score (mTSS). All other statistical analyses are descriptive only. The full analysis set (FAS) was used for all efficacy data, except radiographic data which used the radiographic set (RAD). A logistic regression model was used for the primary and secondary Week 52 analyses and other dichotomous outcomes. CFB in HAQ-DI was analysed using analysis of covariance (ANCOVA) and CFB in mTSS was analysed using ANCOVA on the ranks.

Missing data were imputed using non-responder imputation for analyses on dichotomous outcomes and last observation carried forward for continuous outcomes.

\section{Study procedures and evaluations}

The primary efficacy endpoint was the proportion (\%) of patients in sREM (DAS28(ESR) $<2.6$ at both Weeks 40 and 52). The key secondary endpoint was the proportion (\%) of patients in sLDA (DAS28(ESR) $\leq 3.2$ at both Weeks 40 and 52). Other secondary endpoints in the hierarchical testing procedure were ACR50 response, CFB in HAQ-DI and CFB in mTSS, all at Week 52 .
Secondary outcomes evaluated outside the hierarchical testing procedure included: radiographic non-progression (CFB in mTSS $\leq 0.5)$ and the proportion of patients with HAQ-DI normative function (HAQ-DI $\leq 0.5$ ) at Week 52, CFB in HAQ-DI, DAS28(ESR) and ACR20/50/70 responses, the proportion of patients in remission by ACR/EULAR 2011 criteria, ${ }^{11}$ DAS28 (ESR) <2.6, Clinical Disease Activity Index (CDAI) $\leq 2.8$ and Simplified Disease Activity Index (SDAI) $\leq 3.3$ at Weeks 12, 24 and 52 (additional visits exploratory).

For the subgroup analyses, geographical regions were predefined according to their sociodemographic similarity, similar treatment guidelines (ie, EULAR/ACR treatment guidelines) and their similar patient numbers.

Safety analysis included all adverse events (AEs), serious AEs (SAEs) and clinical laboratory measurements. Incidence rates (IRs) were calculated per 100 patient-years (PY), with 95\% CIs.

\section{RESULTS}

\section{Patient disposition and BL characteristics}

Six hundred and sixty patients received CZP+MTX and 219 patients received $\mathrm{PBO}+\mathrm{MTX}$ (figure 1). Of these, 655 patients 

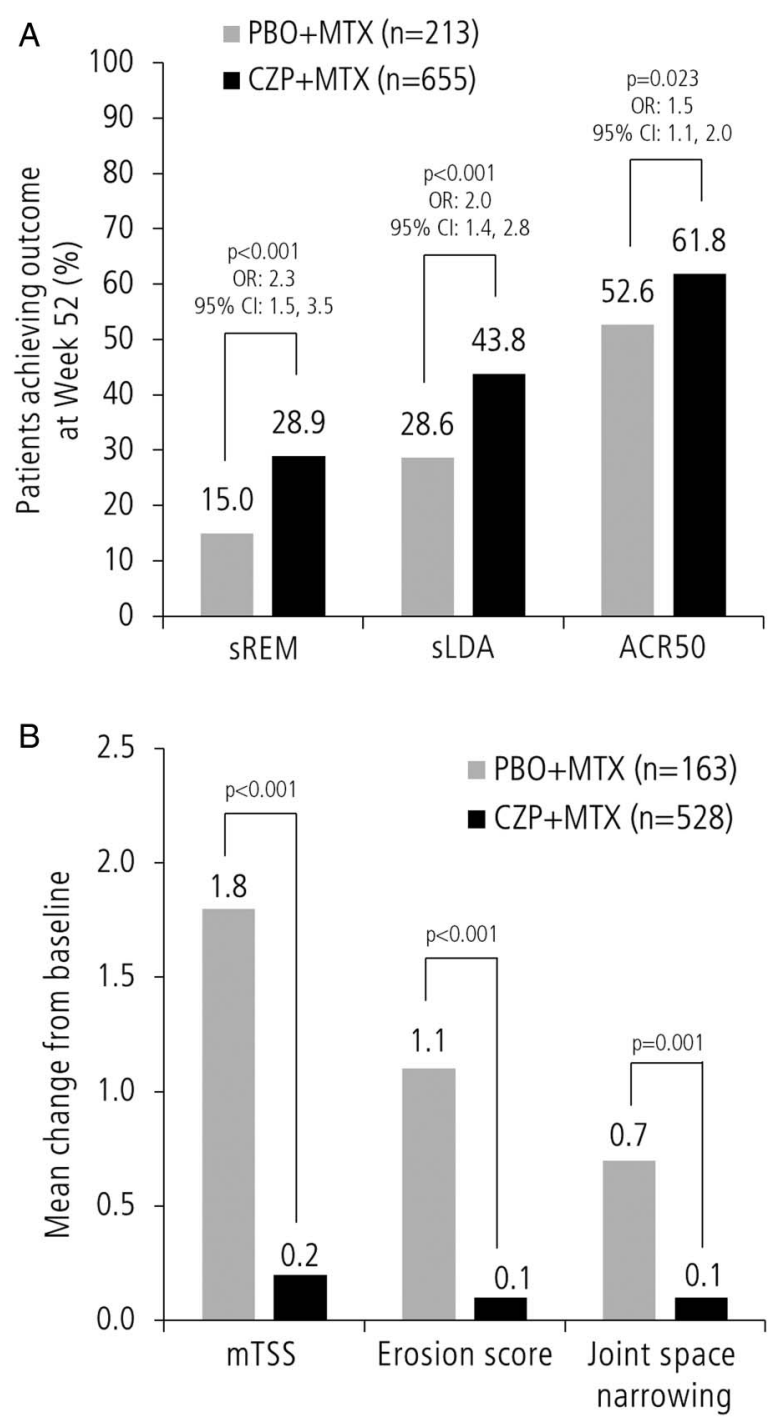

Figure 2 (A) Sustained remission (sREM), sustained low disease activity (sLDA) and American College of Rheumatology (ACR) 50 response at Week 52 . The results are shown for FAS; SREM was defined as DAS28(ESR) <2.6 at Week 40 and Week 52; sLDA was defined as DAS28(ESR) $\leq 3.2$ at Week 40 and Week 52; non-responder imputation was used for missing data and ORs were estimated by logistic regression adjusted for treatment, geographic region and rheumatoid arthritis (RA) disease duration at baseline (BL). (B) The mean change from $B L$ in van der Heijde modified total Sharp score (mTSS), erosion score and joint space narrowing at Week 52. The results are shown for RAD. Missing data (for patients who withdrew early) were imputed by linear extrapolation; data were analysed by analysis of covariance on the ranks with treatment, geographic region and RA disease duration at $B L$ as factors and $B L$ rank value as covariate; $p$ values for erosion score and joint space narrowing are nominal only. CZP, certolizumab pegol; FAS, full analysis set; MTX, methotrexate; OR, odds ratio; PBO, placebo; RAD, radiographic set.

in the CZP+MTX group and 213 in the PBO+MTX group were included in the FAS; $528 \mathrm{CZP}+\mathrm{MTX}$ and $163 \mathrm{PBO}$ + MTX patients were included in the RAD (a summary of RAD $\mathrm{BL}$ radiographic characteristics is listed in online supplementary table S1). The safety set (SS) included $659 \mathrm{CZP}+\mathrm{MTX}$ and 217 $\mathrm{PBO}+\mathrm{MTX}$ patients. In the randomised set (RS), the proportion of patients discontinuing treatment by Week 52 was lower in the CZP+MTX group (24.2\%) than in the PBO+MTX group (34.7\%). The most common reasons for discontinuation

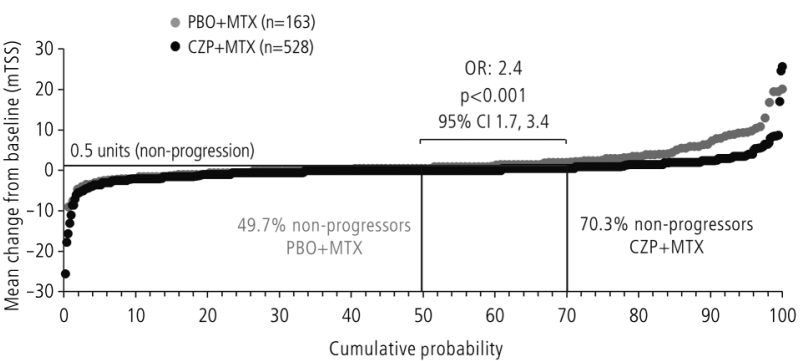

Figure 3 Cumulative probability plot of mean change from baseline in van der Heijde modified total Sharp score (mTSS) at Week 52. RAD; linear extrapolation; $p$ values are nominal only. CZP, certolizumab pegol; MTX, methotrexate; PBO, placebo; RAD, radiographic set.

were AEs (7.7\% CZP+MTX vs 7.8\% $\mathrm{PBO}+\mathrm{MTX})$, consent withdrawal $(5.3 \%$ vs $6.8 \%)$ and 'other' (including some mandatory withdrawals at Weeks 24 and 36). BL characteristics were balanced between treatment arms, with most patients presenting with high disease activity (DAS28(ESR) >5.1), erosions and positivity for RF and ACPA early in the disease course (within 4 months after diagnosis; table 1 ).

The mean maximum-tolerated dose of MTX (optimised MTX) achieved by Week 8 was $21 \mathrm{mg} /$ week for the CZP group and $22 \mathrm{mg} /$ week for the PBO group.

\section{Efficacy}

The C-EARLY study met its primary endpoint: treatment of DMARD-naïve patients with RA with CZP+MTX significantly reduced disease activity and sustained clinical response compared with PBO+MTX. At Week 52, sREM was achieved by 28.9\% CZP+MTX patients versus 15.0\% PBO+MTX patients $(\mathrm{p}<0.001)$, while sLDA was achieved by $43.8 \%$ CZP + MTX patients versus $28.6 \%$ in the $\mathrm{PBO}+\mathrm{MTX}$ group $(\mathrm{p}<0.001$; figure $2 \mathrm{~A})$. The similar results obtained for the sensitivity analysis on the 52-week completer group (sREM: $37.8 \%$ CZP + MTX vs 22.4\% PBO+MTX, p<0.001; sLDA: 57.4\% CZP + MTX vs $42.7 \%$ PBO+MTX, $\mathrm{p}=0.002$ ) suggest that withdrawals did not significantly bias the results.

All secondary endpoints showed statistically significant differences for CZP+MTX versus PBO+MTX at Week 52, respectively: more patients achieved ACR50 response $(61.8 \%$ vs $52.6 \%, \mathrm{p}=0.023$; figure $2 \mathrm{~A}$ ), greater improvements in physical function (CFB in HAQ-DI: -1.00 vs -0.82 , p < 0.001; HAQ-DI normative function: $48.1 \%$ vs $35.7 \%, \mathrm{p}=0.002$ ) and significant inhibition of radiographic progression (CFB in mTSS: 0.2 vs $1.8, \mathrm{p}<0.001$, figure $2 \mathrm{~B}$ ). Mean changes from $\mathrm{BL}$ in joint erosion score and joint space narrowing score were smaller for $\mathrm{CZP}+\mathrm{MTX}$ versus $\mathrm{PBO}+\mathrm{MTX}$ (figure $2 \mathrm{~B}$ ). The proportion of patients with radiographic non-progression was significantly higher for CZP+MTX than for PBO+MTX (figure 3). When alternative definitions of remission were used, the proportion of patients in clinical remission at Week 52 by DAS28(ESR) $<2.6$, ACR/EULAR criteria, CDAI $\leq 2.8$ and SDAI $\leq 3.3$ was significantly greater for CZP+MTX compared with $\mathrm{PBO}+\mathrm{MTX}$ (figure 4A).

Physical function (as measured by HAQ-DI) improved over time in the CZP+MTX group through Week 52; a similar trend was observed in the $\mathrm{PBO}+\mathrm{MTX}$ group, but with a consistently smaller improvement from $\mathrm{BL}$ at each time point (figure $4 \mathrm{~B}$ and see online supplementary figure S2).

A higher proportion of patients achieved LDA (DAS28(ESR) $\leq 3.2)$ at individual time points from Week $2(8.4 \%$ vs $1.4 \%$, 


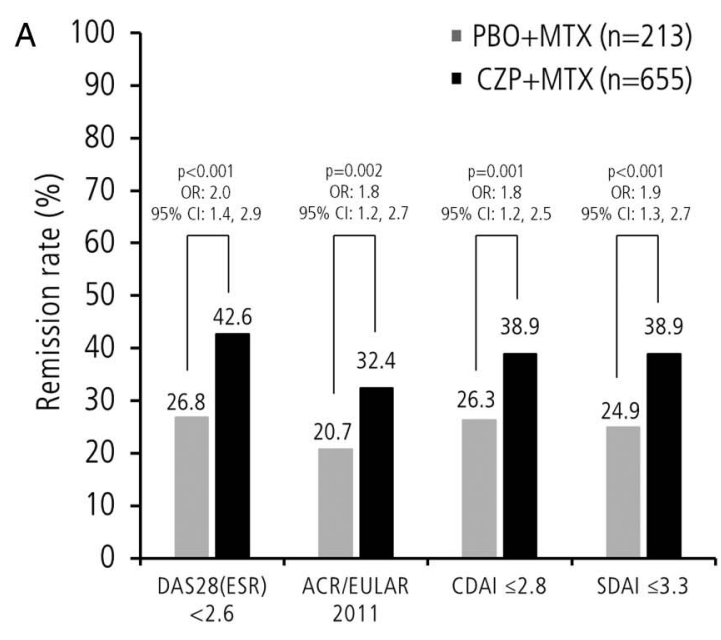

B
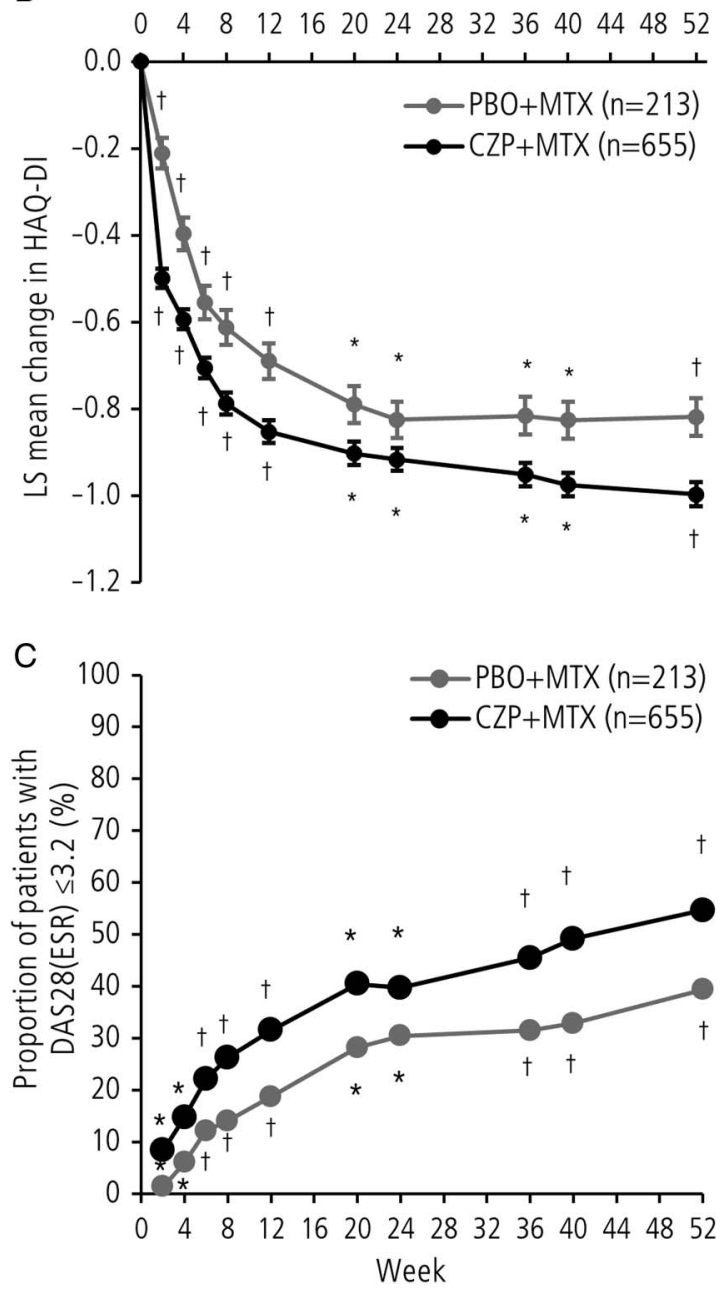

Figure 4 (A) Proportion of patients in remission (various definitions) at Week 52. The results are shown for FAS, non-responder imputation was used for missing data and ORs are estimated by logistic regression; $p$ values shown are nominal only. (B) The mean change from baseline in Health Assessment Questionnaire-Disability Index (HAQ-DI) by visit. FAS, last observation carried forward; nominal $p$ values are estimated by logistic regression: ${ }^{*} p \leq 0.05,{ }^{\dagger} p<0.001$. (C) Proportion of patients in DAS28(ESR) low disease activity by visit. FAS, NRI; nominal $p$ values are estimated by logistic regression: ${ }^{*} p \leq 0.05,{ }^{\dagger} p<0.001$. ACR, American College of Rheumatology; CDAl, Clinical Disease Activity Index; CZP, certolizumab pegol; EULAR, European League Against Rheumatism; FAS, full analysis set; LS, least squares; MTX, methotrexate; OR, odds ratio; PBO, placebo; SDAI, Simplified Disease Activity Index. $\mathrm{p}=0.002)$ in the CZP+MTX group compared with the PBO + MTX group, with the absolute percentage and mean difference between groups slowly increasing to Week 52 (54.7\% CZP + MTX vs 39.4\% PBO+MTX, p<0.001; figure 4C and see online supplementary figure $\mathrm{S} 3$ ).

ACR20/50/70 response rates showed a separation of CZP + MTX treatment from PBO+MTX as early as Week 2 and was sustained to Week 52 for ACR50/70 (figure 5). From Week 6 onwards, there was no statistical difference between CZP + MTX and PBO+MTX in ACR20 response.

A greater decrease in disease activity (measured by CFB in DAS28(ESR)) was observed for CZP+MTX compared with $\mathrm{PBO}+\mathrm{MTX}$ as early as Week $2(\mathrm{p}<0.001)$ and continued to Week 52 (the mean CFB (SE) at Week 52: -3.6 (0.1), CZP + MTX vs -3.0 (0.1) PBO+MTX, p<0.001; mean DAS28 (ESR) values are shown in table 2). Similar trends from Week 2 through Week 52 were observed in CDAI, SDAI, TJC, SJC, ESR and CRP (table 2).

\section{Subgroup analyses}

Analyses of subgroups defined by disease duration were carried out on the primary and secondary endpoints. For almost all endpoints, differences were in favour of CZP+MTX for patients with both $\leq 4$ months $(75.9 \%$ of patients) and $>4$ months (24.1\% of patients) since RA diagnosis, although for ACR50 in the $>4$ months subgroup, no difference was observed between $\mathrm{CZP}+\mathrm{MTX}$ and $\mathrm{PBO}+\mathrm{MTX}$. Forest plots demonstrated that patients in the $\leq 4$ months subgroup had a greater response to CZP treatment (online supplementary figure S4 presents key categorical endpoints and forest plots; online supplementary figure S5 details mean changes from BL in mTSS; interpretation was limited due to the low number of patients in the $>4$ months subgroups).

According to the logistic regression model, improvements in sREM with CZP+MTX versus PBO+MTX differed by geographical region, with greater improvements seen in Europe and Australia $\quad(38.4 \% \quad$ CZP+MTX $\quad$ vs $\quad 16.8 \% \quad$ PBO+MTX; $\mathrm{OR}=3.07,95 \% \mathrm{CI}(1.77$ to 5.34$), \mathrm{p}<0.001)$ than in Latin and North America (17.6\% CZP+MTX vs 13.2\% PBO+MTX; $\mathrm{OR}=1.43,95 \%$ CI (0.75 to 2.70$), \mathrm{p}=0.28)$.

\section{Safety}

The incidence of AEs was similar for both treatment arms (table 3). The most frequently reported AEs in the CZP+MTX group were nausea, upper respiratory tract infection, urinary tract infection, nasopharyngitis, headache and increased levels of alanine aminotransferase (MedDRA preferred terms). Withdrawals due to AEs occurred for 57 (8.6\%) CZP+MTX patients versus $20(9.2 \%) \mathrm{PBO}+\mathrm{MTX}$ patients. The overall rates of SAEs were similar between treatment groups (CZP +MTX: 70 (10.6\%); PBO+MTX: 20 (9.2\%)).

The IR of infection was higher with CZP+MTX (71.8/ $100 \mathrm{PY}, 95 \%$ CI (63.9 to 80.4)) than PBO+MTX (52.7/100 PY, $95 \%$ CI (41.5 to 66.0$)$ ), while the incidence of serious infection was similar in both groups $(3.3 / 100 \mathrm{PY}(2.0,5.2)$ vs $3.7 / 100 \mathrm{PY}$ $(1.5,7.6)$, respectively). The IR of opportunistic infections was higher in the CZP+MTX group (0.2/100 PY, 95\% CI $(0.0$ to 0.9)) with no cases in the PBO+MTX group. One case of disseminated mycobacterium infection was reported in the CZP + MTX group. The mycobacterial strain was not characterised by PCR.

There were two deaths reported in the CZP+MTX group: one stroke, not considered related to study medication, and one case of disseminated, non-characterised, mycobacterium 
Figure 5 Percentage of patients with American College of Rheumatology (ACR)20/50/70 response by visit. The results are shown for FAS and nonresponder imputation was used for missing data; nominal $p$ value between groups are estimated by logistic regression: ${ }^{*} \mathrm{p} \leq 0.05$ at Weeks 2,4 and 40 (ACR20); ${ }^{\dagger} p \leq 0.05$ at Weeks $2,4,6$, $8,12,20,40$ and 52 (ACR50); ${ }^{\ddagger} \mathrm{p} \leq 0.05$ at all time points (ACR70). CZP, certolizumab pegol; FAS, full analysis set; MTX, methotrexate; PBO, placebo.

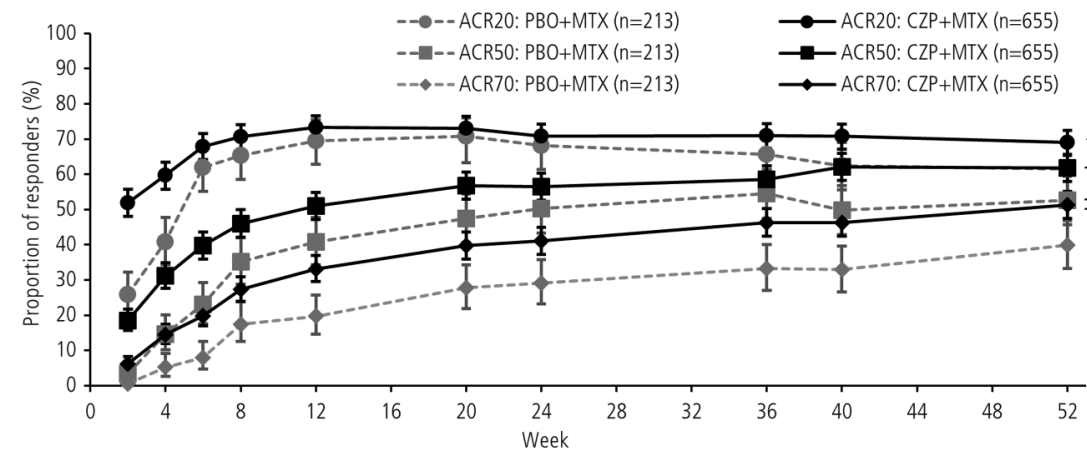

$\begin{array}{lccccccccccc} & & \text { Week 2 } & \text { Week 4 } & \text { Week 6 } & \text { Week 8 } & \text { Week 12 } & \text { Week 20 } & \text { Week 24 } & \text { Week 36 } & \text { Week 40 } & \text { Week 52 } \\ \text { ACR20 } & \text { PBO+MTX } & 25.8 & 40.8 & 62.0 & 65.3 & 69.5 & 70.0 & 68.1 & 65.7 & 62.4 & 61.5 \\ (\%) & \text { CZP+MTX } & 51.9 & 59.7 & 67.9 & 70.7 & 73.3 & 73.1 & 70.8 & 71.0 & 70.8 & 69.0 \\ \text { ACR50 } & \text { PBO+MTX } & 3.3 & 14.6 & 23.0 & 35.2 & 40.8 & 47.4 & 50.2 & 54.5 & 49.8 & 52.6 \\ (\%) & \text { CZP+MTX } & 18.5 & 31.1 & 39.7 & 46.0 & 51.0 & 56.8 & 56.5 & 58.6 & 62.1 & 61.8 \\ \text { ACR70 } & \text { PBO+MTX } & 0.5 & 5.2 & 8.0 & 17.4 & 19.7 & 27.7 & 29.1 & 33.3 & 32.9 & 39.9 \\ (\%) & \text { CZP+MTX } & 6.1 & 14.5 & 19.8 & 27.3 & 33.1 & 39.7 & 41.1 & 46.3 & 46.3 & 51.3\end{array}$

infection (reported above) primarily localised in the peritoneum (peritonitis with extensive granulomas which stained positive for acid-fast bacillus) with acute respiratory distress, considered by the investigator to be study medication related. Notably, the BL chest X-ray and QuantiFERON test were both negative. The one death in the PBO+MTX group was not considered to be related to study medication (respiratory failure).

\section{DISCUSSION}

C-EARLY is the first report of a double-blind, randomised PBO-controlled study assessing the efficacy and safety of CZP +optimised MTX in DMARD-naïve patients with early RA with poor prognostic factors, using a stringent primary outcome of sREM. These data demonstrate that CZP+MTX combination therapy results in a significantly higher proportion of patients

Table 2 Mean disease activity at key study visits

\begin{tabular}{|c|c|c|c|c|c|}
\hline & Baseline & Week 2 & Week 12 & Week 24 & Week 52 \\
\hline \multicolumn{6}{|l|}{ DAS28(ESR) } \\
\hline PBO+MTX (SD) & $6.80(0.91)$ & $5.91(1.28)$ & $4.43(1.46)$ & $4.07(1.44)$ & $3.77(1.68)$ \\
\hline $\mathrm{CZP}+\mathrm{MTX}(\mathrm{SD})$ & $6.70(0.89)$ & $5.06(1.27)$ & 3.88 (1.44) & 3.54 (1.47) & 3.11 (1.58) \\
\hline $\mathrm{p}$ Value (CFB) & - & $<0.001$ & $<0.001$ & $<0.001$ & $<0.001$ \\
\hline \multicolumn{6}{|l|}{ CDAI } \\
\hline PBO+MTX (SD) & $42.64(12.87)$ & $31.52(14.85)$ & $17.20(13.69)$ & 14.11 (12.99) & $13.08(13.72)$ \\
\hline CZP+MTX (SD) & $41.28(12.52)$ & $23.74(12.87)$ & 13.33 (11.99) & $10.79(11.27)$ & 8.71 (11.65) \\
\hline p Value (CFB) & - & $<0.001$ & $<0.001$ & 0.001 & $<0.001$ \\
\hline \multicolumn{6}{|l|}{ SDAI } \\
\hline PBO+MTX (SD) & $44.79(13.91)$ & 33.38 (15.84) & 18.32 (14.39) & $15.08(13.65)$ & $14.05(14.29)$ \\
\hline CZP+MTX (SD) & $43.46(13.56)$ & $24.41(13.08)$ & $14.10(12.63)$ & $11.55(12.00)$ & $9.43(12.41)$ \\
\hline p Value (CFB) & - & $<0.001$ & $<0.001$ & $<0.001$ & $<0.001$ \\
\hline \multicolumn{6}{|l|}{ TJC } \\
\hline PBO+MTX (SD) & $16.22(6.45)$ & $12.37(7.28)$ & $6.20(6.32)$ & $5.08(6.09)$ & $4.76(6.10)$ \\
\hline $\mathrm{CZP}+\mathrm{MTX}(\mathrm{SD})$ & $15.61(6.48)$ & $9.21(6.76)$ & $5.13(5.86)$ & $4.08(5.63)$ & $3.27(5.39)$ \\
\hline p Value (CFB) & - & $<0.001$ & 0.055 & 0.060 & 0.002 \\
\hline \multicolumn{6}{|l|}{ SJC } \\
\hline PBO+MTX (SD) & $13.04(5.64)$ & $8.99(6.02)$ & $5.09(5.38)$ & $3.89(4.58)$ & $3.60(4.51)$ \\
\hline CZP+MTX (SD) & $12.37(5.48)$ & $6.77(4.86)$ & $3.25(4.24)$ & $2.61(3.83)$ & 2.06 (3.94) \\
\hline $\mathrm{p}$ Value (CFB) & - & $<0.001$ & $<0.001$ & $<0.001$ & $<0.001$ \\
\hline \multicolumn{6}{|l|}{$\mathrm{ESR}^{*}$} \\
\hline PBO+MTX (min, max) & $44.00(10.0,135.0)$ & $41.00(4.0,140.0)$ & $30.00(1.0,100.0)$ & $30.00(2.0,137.0)$ & $21.50(2.0,110.0)$ \\
\hline $\mathrm{CZP}+\mathrm{MTX}(\min , \max )$ & $42.00(2.0,150.0)$ & $29.00(1.0,130.0)$ & $22.00(0.0,150.0)$ & $20.00(0.0,150.0)$ & $17.00(0.0,150.0)$ \\
\hline p Value (CFB) & - & $<0.001$ & $<0.001$ & $<0.001$ & $<0.001$ \\
\hline \multicolumn{6}{|l|}{ CRP* } \\
\hline PBO+MTX (min, max) & $10.51(0.3,243.2)$ & $8.35(0.3,231.2)$ & $4.69(0.2,157.8)$ & $3.74(0.2,157.8)$ & $3.96(0.2,157.8)$ \\
\hline $\mathrm{CZP}+\mathrm{MTX}(\min , \max )$ & $11.14(0.2,231.1)$ & $2.17(0.1,237.2)$ & $2.33(0.1,170.6)$ & $2.05(0.2,251.8)$ & $2.07(0.1,251.8)$ \\
\hline p Value (CFB) & - & $<0.001$ & $<0.001$ & $<0.001$ & $<0.001$ \\
\hline
\end{tabular}

${ }^{*}$ Median values; PBO+MTX $n=213, C Z P+M T X n=655 ; p$ values are nominal and describe the difference in CFB between the two study arms at each study visit; LOCF; FAS.

CFB, change from baseline; CDAI, Clinical Disease Activity Index; CRP, C reactive protein; CZP, certolizumab pegol; ESR, erythrocyte sedimentation rate; FAS, full analysis set; LOCF, last observation carried forward; MTX, methotrexate; PBO, placebo; SDAI, Simplified Disease Activity Index; SJC, swollen joint count; TJC, tender joint count. 


\begin{tabular}{|c|c|c|c|c|}
\hline \multirow[t]{2}{*}{$\begin{array}{l}\text { Total patient-years (PY) at risk (per } 100 \text { PY) } \\
\text { Median exposure (days) }\end{array}$} & \multicolumn{2}{|c|}{$\begin{array}{c}\mathrm{PBO}+\mathrm{MTX} \\
\mathrm{n}=217 \\
1.93 \\
364.0\end{array}$} & \multicolumn{2}{|c|}{$\begin{array}{c}C Z P+M T X \\
n=659 \\
6.05 \\
364.0\end{array}$} \\
\hline & n (\%) & $\begin{array}{c}\text { IR } \\
(95 \% \mathrm{Cl})\end{array}$ & n (\%) & $\begin{array}{c}\mathrm{IR} \\
(95 \% \mathrm{Cl})\end{array}$ \\
\hline Any TEAE ( $\geq 5 \%$ in any SOC) & $158(72.8)$ & 195.6 (166.3 to 228.7$)$ & $525(79.7)$ & 250.8 (229.8 to 273.2$)$ \\
\hline Blood and lymphatic system disorders & $13(6.0)$ & 6.9 (3.7 to 11.8$)$ & $45(6.8)$ & $7.8(5.7$ to 10.4$)$ \\
\hline Eye disorders & $13(6.0)$ & $7.0(3.8$ to 12.0$)$ & $24(3.6)$ & 4.1 (2.6 to 6.1$)$ \\
\hline Gastrointestinal disorders & $53(24.4)$ & 34.0 (25.5 to 44.5$)$ & $206(31.3)$ & 44.7 (38.8 to 51.3$)$ \\
\hline General disorders and administration site conditions & $27(12.4)$ & $15.4(10.2$ to 22.5$)$ & $108(16.4)$ & 20.2 (16.6 to 24.4$)$ \\
\hline Infections and infestations & $76(35.0)$ & $52.7(41.5$ to 66.0$)$ & $298(45.2)$ & 71.8 (63.9 to 80.4$)$ \\
\hline Injury, poisoning and procedural complications & $15(6.9)$ & $8.2(4.6$ to 13.5$)$ & $62(9.4)$ & $10.9(8.4$ to 14.0$)$ \\
\hline Investigations & $42(19.4)$ & $25.2(18.2$ to 34.1$)$ & $137(20.8)$ & 26.4 (22.1 to 31.2$)$ \\
\hline Metabolism and nutrition disorders & $12(5.5)$ & 6.5 (3.3 to 11.3$)$ & $57(8.6)$ & $10.0(7.6$ to 13.0$)$ \\
\hline Musculoskeletal and connective tissue disorders & $36(16.6)$ & 20.5 (14.4 to 28.4$)$ & $114(17.3)$ & $21.2(17.5$ to 25.5$)$ \\
\hline Nervous system disorders & $26(12.0)$ & 14.9 (9.7 to 21.8$)$ & $92(14.0)$ & 17.1 (13.8 to 20.9$)$ \\
\hline Respiratory, thoracic and mediastinal disorders & $22(10.1)$ & $12.3(7.7$ to 18.6$)$ & $76(11.5)$ & $13.6(10.7$ to 17.0$)$ \\
\hline Skin and subcutaneous tissue disorders & $31(14.3)$ & 18.2 (12.4 to 25.8$)$ & $119(18.1)$ & 22.5 (18.6 to 26.9$)$ \\
\hline Vascular disorders & $9(4.1)$ & 4.8 (2.2 to 9.2$)$ & $39(5.9)$ & 6.7 (4.8 to 9.2$)$ \\
\hline Serious TEAEs, $\mathrm{n}(\%)$ & $20(9.2)$ & 10.7 (6.6 to 16.6$)$ & $70(10.6)$ & 12.1 (9.4 to 15.2$)$ \\
\hline Infections and infestations & $7(3.2)$ & $3.7(1.5$ to 7.6$)$ & $20(3.0)$ & $3.3(2.0$ to 5.2$)$ \\
\hline Active tuberculosis (TB)* & $0(0.0)$ & - & $1(0.2)$ & $0.2(0.0$ to 0.9$)$ \\
\hline Drug-related TEAEs & $69(31.8)$ & - & $278(42.2)$ & - \\
\hline TEAEs leading to discontinuation & $20(9.2)$ & $10.6(6.5$ to 16.4$)$ & 57 (8.6) & $9.6(7.3$ to 12.4$)$ \\
\hline TEAEs requiring dose change of MTX & $14(6.5)$ & - & $73(11.1)$ & - \\
\hline TEAEs leading to death & $1(0.5)$ & $0.5(0.0$ to 2.9$)$ & $2(0.3)$ & $0.3(0.0$ to 1.2$)$ \\
\hline
\end{tabular}

*Included both pulmonary TB and gastrointestinal TB in the same patient, diagnosis not confirmed by PCR. SS. n, number of patients reporting $\geq 1$ AE in that category. A TEAE was defined as an AE starting on or after the date of first study medication administration and up to 70 days after the last (most recent) CZP or PBO dose. AEs with a missing relationship to study medication were counted as related. MedDRA v17.0.

$A E$, adverse event; CZP, certolizumab pegol; IR, incidence rate; MTX, methotrexate; PBO, placebo; SOC, system organ class; SS, safety set; TEAE, treatment emergent adverse event.

achieving sREM than those treated with PBO+MTX, even when using a 'treat-to-tolerance' dosing strategy for MTX. Significant improvements in physical function and inhibition of structural damage were observed for CZP+MTX patients. Consequently, for patients with poor prognostic factors for severe disease progression, treating early and aggressively may represent a unique opportunity to achieve maximal clinical benefit.

Advances in the treatment options for RA, including DMARDs and biologic DMARDs/anti-TNFs, have made clinical remission and radiographic non-progression an achievable target. ${ }^{12}$ In this study, MTX titration was an important component of treatment and ensured that each patient received the maximum-tolerated MTX dose within the first 8 weeks (between $\geq 15$ and $\leq 25 \mathrm{mg} /$ week), which we refer to as optimised MTX. To our knowledge, there are no previous studies in MTX-naïve or DMARD-naïve patients with RA where MTX doses have been optimised per-protocol to the levels achieved in C-EARLY. This optimisation may have been responsible, in part, for the response observed for the PBO+MTX and CZP+MTX arms. Optimisation of MTX is not specifically stated in treat-to-target guidelines; however, the mean doses achieved are consistent with international recommendations. ${ }^{13}$

In addition to sREM, this study also evaluated the rate of remission using alternative remission criteria, including DAS28(ESR), CDAI, SDAI and ACR/EULAR criteria, with superior results consistently observed for CZP+MTX over $\mathrm{PBO}+\mathrm{MTX}$, supporting the reliability of the recently validated
ACR/EULAR remission definition. ${ }^{14}$ In the C-EARLY trial, despite receiving optimised MTX, a significant proportion of patients were not in remission at Week 52 and an even smaller proportion achieved the primary outcome of sREM. Although patients generally responded well to MTX, which is expected in a DMARD-naïve population of patients, they responded significantly better to $\mathrm{CZP}$, confirming the clinical relevance of our findings.

Treatment of patients very early in the pathogenesis of disease is associated with significantly reduced joint destruction and better clinical outcomes. ${ }^{15}$ The analysis of radiographic data in C-EARLY demonstrates that CZP+MTX therapy can inhibit structural damage significantly more than MTX alone-the percentage of patients with radiographic non-progression was significantly higher in the CZP+MTX group compared with the $\mathrm{PBO}+\mathrm{MTX}$ group. These results are consistent with the C-OPERA trial in Japanese patients with early RA, which showed that CZP+MTX treatment results in greater inhibition of structural damage and higher clinical remission rates than PBO+MTX. ${ }^{9}$

While DAS(ESR) $<2.6$ is a validated measure of clinical remission, consensus has not yet been reached on what constitutes sREM. Until now, the two RA clinical trials that have used sREM as the primary endpoint chose two different definitions. These trials were an open-label study evaluating etanercept tapering $^{6}$ and an open-label study evaluating abatacept withdrawal. ${ }^{16}$ We defined sREM as DAS(ESR) $<2.6$ at Weeks 40 and 52 of treatment. The use of two time points 12 weeks apart was 
meant to reflect RA management goals used in real-world clinical practice. ${ }^{3}$

The rates of sREM observed in C-EARLY $(28.9 \%$ for the $\mathrm{CZP}+\mathrm{MTX}$ arm) were lower than those initially estimated in the power analysis, which were based on Week 52 remission rates of the etanercept COMET trial $(50 \%) .{ }^{17}$ This is most likely a consequence of the use of sREM, which is a more rigorous endpoint than clinical remission; this is supported by C-EARLY Week 52 remission rates $(42 \%$ for the CZP+MTX arm), which were comparable with the remission rates observed in COMET.

Overall, the results from C-EARLY suggest that it is possible to achieve sREM more frequently with combined CZP+MTX treatment than with MTX alone in DMARD-naïve patients with RA. Consistent with our results, other studies have demonstrated greater efficacy of anti-TNFs in combination with MTX in early RA. These have included infliximab $+\mathrm{MTX},{ }^{18}$ adalimumab+MTX, ${ }^{19}$ etanercept + MTX $^{17}{ }^{20}$ and golimumab + MTX. $^{21}$

No new safety signals for CZP+MTX were observed and there was no increase in infection relative to other anti-TNFs in equivalent patient populations with RA. ${ }^{7}$ No increase in overall AEs, SAEs or serious infection events (SIEs) in patients treated with CZP+MTX was seen compared with PBO+MTX. As patients were DMARD-naïve (including MTX) at study entry, their tolerance to MTX treatment could not be anticipated. Thus, the incidence of AEs observed in this study may be partly attributed to the optimised MTX dose. The IR of SIEs with CZP+MTX in this study (3.3/100 PY) was comparable with those reported for other anti-TNFs in combination with MTX in similar patient populations with early RA: adalimumab $+\operatorname{MTX}(2.9 / 100 \mathrm{PY})^{19}$ and infliximab+MTX (5.4/100 PY). ${ }^{22}$ The single CZP-related death in this study occurred in a 65 -year-old patient of Indian origin, with hypertension and diabetes mellitus. The patient died of cardiorespiratory failure and acute respiratory distress syndrome, secondary to septic shock caused by bowel perforations. Acid-fast bacillus stains of the gut and saliva were positive. This, in conjunction with the gut pathology, led to a diagnosis of disseminated, non-characterised, mycobacterium infection; the QuantiFERON test was negative and there was no PCR confirmation of TB.

We conclude that there is a positive benefit-risk ratio associated with CZP treatment in combination with MTX as initial therapy in DMARD-naïve patients within a year of diagnosis of severe, active RA. The beneficial effect of earlier treatment with biologics specifically in patients with poor prognostic factors may be an important consideration in determining the timing of treatment initiation in specific subgroups of patients. Of note, an aggressive combination of CZP with a 'treat-to-tolerance' strategy for MTX at an early stage of disease may contribute to overcome the currently perceived 'efficacy ceiling' for anti-TNFs.

\footnotetext{
Author affiliations

${ }^{1}$ Leeds Institute of Rheumatic and Musculoskeletal Medicine, University of Leeds, Leeds, UK

${ }^{2}$ NIHR Leeds Musculoskeletal Biomedical Research Unit, Leeds Teaching Hospitals NHS Trust, Leeds, UK

${ }^{3}$ Johns Hopkins University, Baltimore, Maryland, USA

${ }^{4}$ Rheumatology and Clinical Immunology, Charité-University Medicine, Berlin, Germany

${ }^{5}$ Division of Rheumatology, Weill Cornell Medical College, Hospital for Special Surgery, New York, New York, USA

${ }^{6}$ Division of Rheumatology, David Geffen School of Medicine at UCLA, Los Angeles, California, USA

${ }^{7}$ Université Paris-Sud, Hôpitaux Universitaires Paris-Sud, AP-HP, Le Kremlin Bicêtre,
} France
${ }^{8}$ Deprtment of Rheumatology, Leiden University Medical Centre, Leiden, The Netherlands

${ }^{9}$ Unit for Clinical Therapy Research, Inflammatory Disease, Karolinska Institute, Stockholm, Sweden

${ }^{10}$ UCB Pharma, Brussels, Belgium

${ }^{11}$ UCB Pharma, Raleigh, North Carolina, USA

${ }^{12}$ Division of Rheumatology, Immunology and Allergy, Brigham and Women's Hospital, Boston, Massachusetts, USA

Correction notice This article has been corrected since it was published Online First. In the penultimate paragraph of the Discussion section the 'IR of SIEs with CZP+MTX in this study' has been corrected to '(3.3/100 PY)'.

Acknowledgements We thank the patients and their caregivers in addition to the investigators and their teams who contributed to this study. The authors acknowledge 'Matladi N. Ndlovu, PhD, UCB Pharma, Brussels, Belgium, for publication critical review coordination and Costello Medical Consulting, UK, for writing and editorial assistance, which was funded by UCB Pharma.

Contributors All the authors made substantial contributions to the evaluation of the study results and to the development and review of the manuscript.

Funding UCB Pharma sponsored the study and the development of the manuscript. In addition to content approval by the authors, UCB signed off on the manuscript following a full review to ensure that the data presented in the publication are scientifically, technically and medically supportable and did not contain any information which has the potential to damage the intellectual property of UCB. Additionally, UCB ensured that the publication complies with applicable laws, regulations, guidelines and good industry practice.

Competing interests PE received consultancy and speaker's fee from Pfizer, MSD, AbbVie, UCB Pharma, Roche, Bristol-Myers Squibb, Schering-Plough, Novartis and Samsung. COBIII received consultancy fees from UCB Pharma. GRB received consultancy fees from AbbVie, MSD, Pfizer, Roche and UCB Pharma. DEF received research grants from Abbott, Actelion, Amgen, Bristol-Myers Squibb, Gilead, GlaxoSmithKline, NIH, Novartis, Pfizer, Roche/Genentech and UCB Pharma; consultancy fees from Abbott, Actelion, Amgen, Bristol-Myers Squibb, Biogen IDEC, Janssen, Gilead, GlaxoSmithKline, NIH, Novartis, Pfizer, Roche/Genentech and UCB Pharma and other fees from Abbott, Actelion, Amgen, Bristol-Myers Squibb, Biogen, IDEC, Janssen, Gilead, NIH, Roche/Genentech, Abbott, Actelion and UCB Pharma. XM received research grants from Pfizer, GlaxoSmithKline and Roche and consultancy fees from Bristol-Myers Squibb, GlaxoSmithKline, Pfizer, Roche, UCB Pharma and Sanofi-Aventis. DvdH received consultancy fees from AbbVie, Amgen, AstraZeneca, Augurex, Bristol-Myers Squibb, Boehringer Ingelheim, Celgene, Centocor, Chugai, Covagen, Daiichi, Eli-Lilly, Galapagos, GlaxoSmithKline, Janssen Merck, Novo-Nordisk, Otsuka, Pfizer, Roche, Sanofi-Aventis, UCB Pharma and Vertex; research grants from AbbVie, Amgen, AstraZeneca, Augurex, Bristol-Myers Squibb, Boehringer Ingelheim, Celgene, Centocor, Chugai, Covagen, Daiichi, Eli-Lilly, Galapagos, GlaxoSmithKline, Janssen, Merck, Novo-Nordisk, Otsuka, Pfizer, Roche, Sanofi-Aventis, UCB Pharma and Vertex and is Director of Imaging at Rheumatology BV. RvV received research support from AbbVie, Bristol-Myers Squibb, GlaxoSmithKline, Pfizer, Roche and UCB Pharma and consultancy fees from AbbVie, Biotest, Bristol-Myers Squibb, GlaxoSmithKline, Janssen, Eli-Lilly, Merck, Pfizer, Roche, UCB Pharma and Vertex. CA is an employee of UCB Pharma. IM is an employee of UCB Pharma. OP is an employee of UCB Pharma. $D T$ is an employee of UCB Pharma. BV is an employee of UCB Pharma. MEW received research grants from Amgen, Bristol-Myers Squibb, Crescendo Bioscience and UCB Pharma and consultancy fees from AbbVie, Amgen, AstraZeneca,

Bristol-Myers Squibb, Crescendo Bioscience, Eli-Lilly, Medlmmune, Merck, Novartis, Pfizer, Roche and UCB Pharma.

Ethics approval This study was conducted in accordance with the current version of the applicable regulatory and International Conference on Harmonisation (ICH)-Good Clinical Practice (GCP) requirements, the ethical principles that have their origin in the principles of the Declaration of Helsinki and the local laws of the countries involved.

Provenance and peer review Not commissioned; externally peer reviewed.

Open Access This is an Open Access article distributed in accordance with the Creative Commons Attribution Non Commercial (CC BY-NC 4.0) license, which permits others to distribute, remix, adapt, build upon this work non-commercially, and license their derivative works on different terms, provided the original work is properly cited and the use is non-commercial. See: http://creativecommons.org/ licenses/by-nc/4.0/

\section{REFERENCES}

1 Schoels M, Knevel R, Aletaha D, et al. Evidence for treating rheumatoid arthritis to target: results of a systematic literature search. Ann Rheum Dis 2010;69:638-43. 
2 Singh JA, Furst DE, Bharat A, et al. 2012 update of the 2008 American College of Rheumatology recommendations for the use of disease-modifying antirheumatic drugs and biologic agents in the treatment of rheumatoid arthritis. Arthritis Care Res (Hoboken) 2012;64:625-39.

3 Smolen JS, Aletaha D, Bijlsma JW, et al. Treating rheumatoid arthritis to target: recommendations of an international task force. Ann Rheum Dis 2010;69:631-7.

4 van Vollenhoven RF, Nagy G, Tak PP. Early start and stop of biologics: has the time come? BMC Med 2014;12:25.

5 Emery P, Kvien TK, Combe B, et al. Combination etanercept and methotrexate provides better disease control in very early ( $<=4$ months) versus early rheumatoid arthritis ( $>4$ months and $<2$ years): post hoc analyses from the COMET study. Ann Rheum Dis 2012;71:989-92.

6 Emery P, Hammoudeh M, FitzGerald 0 , et al. Sustained remission with etanercept tapering in early rheumatoid arthritis. N Engl J Med 2014;371:1781-92.

7 Keystone $\mathrm{E}$, van der Heijde, Mason D Jr, et al. Certolizumab pegol plus methotrexate is significantly more effective than placebo plus methotrexate in active rheumatoid arthritis: findings of a fifty-two-week, phase III, multicenter, randomized, double-blind, placebo-controlled, parallel-group study. Arthritis Rheum 2008;58:3319-29.

8 Smolen J, Landewé RB, Mease P, et al. Efficacy and safety of certolizumab pegol plus methotrexate in active rheumatoid arthritis: the RAPID 2 study. A randomised controlled trial. Ann Rheum Dis 2009;68:797-804.

9 Atsumi T, Yamamoto K, Takeuchi T, et al. The first early rheumatoid arthritis, certolizumab pegol multicenter, double-blind, randomized, parallel-group study: C-OPERA, in patients fulfilling the 2010 ACR/EULAR classification criteria, demonstrates inhibition of joint damage progression. Ann Rheum Dis 2014;73(Suppl 2):484.

10 Aletaha D, Neogi T, Silman AJ, et al. 2010 rheumatoid arthritis classification criteria: an American College of Rheumatology/European League Against Rheumatism collaborative initiative. Ann Rheum Dis 2010;69:1580-8.

11 Felson DT, Smolen JS, Wells G, et al. American College of Rheumatology/European League against Rheumatism provisional definition of remission in rheumatoid arthritis for clinical trials. Ann Rheum Dis 2011;70:404-13.

12 Singh JA, Saag KG, Bridges SL Jr, et al. 2015 American College of Rheumatology Guideline for the treatment of rheumatoid arthritis. Arthritis Rheumatol 2016;68:1-26.

13 Visser K, Katchamart W, Loza E, et al. Multinational evidence-based recommendations for the use of methotrexate in rheumatic disorders with a focus on rheumatoid arthritis: integrating systematic literature research and expert opinion of a broad international panel of rheumatologists in the $3 \mathrm{E}$ Initiative. Ann Rheum Dis 2009;68:1086-93.

14 Zhang B, Combe B, Rincheval N, et al. Validation of ACR/EULAR definition of remission in rheumatoid arthritis from RA practice: the ESPOIR cohort. Arthritis Res Ther 2012;14:R156.

15 Cush JJ. Early rheumatoid arthritis - is there a window of opportunity? J Rheumatol Supp/ 2007;80:1-7.

16 Emery P, Burmester GR, Bykerk VP, et al. Evaluating drug-free remission with abatacept in early rheumatoid arthritis: results from the phase $3 \mathrm{~b}$, multicentre, randomised, active-controlled AVERT study of 24 months, with a 12-month, double-blind treatment period. Ann Rheum Dis 2015;74:19-26.

17 Emery P, Breedveld FC, Hall S, et al. Comparison of methotrexate monotherapy with a combination of methotrexate and etanercept in active, early, moderate to severe rheumatoid arthritis (COMET): a randomised, double-blind, parallel treatment trial. Lancet 2008;372:375-82.

18 Quinn MA, Conaghan PG, O'Connor PJ, et al. Very early treatment with infliximab in addition to methotrexate in early, poor-prognosis rheumatoid arthritis reduces magnetic resonance imaging evidence of synovitis and damage, with sustained benefit after infliximab withdrawal: results from a twelve-month randomized, double-blind, placebo-controlled trial. Arthritis Rheum 2005;52:27-35.

19 Breedveld FC, Weisman MH, Kavanaugh AF, et al. The PREMIER study: a multicenter, randomized, double-blind clinical trial of combination therapy with adalimumab plus methotrexate versus methotrexate alone or adalimumab alone in patients with early, aggressive rheumatoid arthritis who had not had previous methotrexate treatment. Arthritis Rheum 2006;54:26-37.

20 Genovese MC, Bathon JM, Martin RW, et al. Etanercept versus methotrexate in patients with early rheumatoid arthritis: two-year radiographic and clinical outcomes. Arthritis Rheum 2002;46:1443-50.

21 Emery $P$, Fleischmann $R$, van der Heijde D, et al. The effects of golimumab on radiographic progression in rheumatoid arthritis: results of randomized controlled studies of golimumab before methotrexate therapy and golimumab after methotrexate therapy. Arthritis Rheum 2011;63:1200-10.

22 St Clair EW, van der Heijde DM, Smolen JS, et al. Combination of infliximab and methotrexate therapy for early rheumatoid arthritis: a randomized, controlled trial. Arthritis Rheum 2004;50:3432-43. 